\title{
A General Semi-Analytical Solution for Three Types of Well Tests in Confined Aquifers with a Partially Penetrating Well
}

\author{
Shaw-Yang Yang $^{1}$ and Hund-Der Yeh ${ }^{2, *}$ \\ ${ }^{1}$ Department of Civil Engineering, Vanung University, Jhongli, Taiwan \\ ${ }^{2}$ Institute of Environmental Engineering, National Chiao Tung University, Hsinchu, Taiwan
}

Received 9 September 2011, accepted 22 May 2012

\begin{abstract}
This note develops a general mathematical model for describing the transient hydraulic head response for constant-head test, constant-flux test, and slug test in a radial confined aquifer system with a partially penetrating well. The Laplace-domain solution for the model is derived by applying the Laplace transform with respect to time and finite Fourier cosine transform with respect to the $z$-direction. This new solution has been shown to reduce to the constant-head test when discounting the wellbore storage and maintaining a constant well water level. This solution can also be reduced to the constant-flux test solution when discounting the wellbore storage and keeping a constant pumping rate in the well. Moreover, the solution becomes the slug test solution when there is no pumping in the well. This general solution can be used to develop a single computer code to estimate aquifer parameters if coupled with an optimization algorithm or to assess the effect of well partial penetration on hydraulic head distribution for three types of aquifer tests.
\end{abstract}

Key words: Pumping test, Slug test, Semi-analytical solution, Laplace transform, Finite Fourier cosine transform, Well partial penetration Citation: Yang, S. Y. and H.D. Yeh, 2012: A general semi-analytical solution for three types of well tests in confined aquifers with a partially penetrating well. Terr. Atmos. Ocean. Sci., 23, 577-584, doi: 10.3319/TAO.2012.05.22.02(WMH)

\section{INTRODUCTION}

The constant-head and constant-flux tests are two typical aquifer tests in site characterization. The constant-head test is carried out in a single well which needs to maintain a constant head inside the well and measure the transient flow rate across the wellbore. This test is suitable to use in low permeability formations for estimating aquifer parameters (e.g., transmissivity and storage coefficient). On the other hand, the constant-flux test requires maintaining a constant rate of well extraction or injection and measures the change of the hydraulic head at the observation well. Slug test is another kind of aquifer tests commonly utilized for the estimation of aquifer parameters. This test is performed by instantaneous extracting/injecting a small volume of water from/into the well and measuring the change of well water level simultaneously. The aquifer parameters can then be obtained from the analysis of the measured test data using a graphical method or computer method (Yeh 1987). The slug

\footnotetext{
* Corresponding author

E-mail:hdyeh@mail.nctu.edu.tw
}

test is widely used to estimate the aquifer parameters due to the advantages of low cost, ease of implementation and short test duration, absence of need for post-treatment of a large volume of contaminated water, and relatively minor disturbance to the groundwater flow system.

Under field conditions, the test well may partially penetrate the thickness of the aquifer. The flow toward a fully penetrating well is expected to be a horizontal flow; in contrast, the flow toward a partially penetrating well includes both the horizontal and vertical flows. A partially penetrating well is commonly installed in an aquifer that is relatively thick or adapted for the investigation of groundwater contamination. The change of well water levels would be influenced by the well characteristics such as the length and position of the well screen during the test. Thus, the results of the data analysis obtained from any one of the aquifer tests may lead to significant estimation errors if the effect of well partial penetration is not considered.

For the constant-head test, the early works involved in the development of solutions for confined radial aquifer 
systems with well partial penetration were Kirkham (1959), Novakowski (1993), Cassiani et al. (1999), Chang and Chen (2002), Yang and Yeh (2005) among many others. Kirkham (1959) divided the flow model into two different regions and derived a steady-state solution for groundwater distribution in a confined aquifer when performing the constanthead test at a partially penetrating well. Novakowski (1993) presented a mathematical model for aquifers by considering the effects of finite-thickness skin and well partial penetration. He provided a Laplace-domain solution of transient flow rate and curves of hydraulic head versus time to investigate the influences of finite-thickness skin and well partial penetration on the hydraulic head distribution. Cassiani et al. (1999) derived a semi-analytical solution for a mixed boundary value problem to describe the pumping at a partially penetrating well with an infinitesimal skin in an anisotropic aquifer of infinite vertical extent. Chang and Chen (2002) used the same mathematical model as Cassiani et al. (1999) except that the aquifer is of finite thickness in the vertical direction and the flux entering through the well screen is a function of time and location along the screen. Yang and Yeh (2005) provided an analytical solution for a constant-head test performed at a partially penetrating well under the effect of the finite-thickness skin. An efficient numerical method for computing the solutions was also presented.

Hantush published a series of articles (Hantush 1957, 1961a, b, 1964) presenting solutions to describe the drawdown distribution around a partially penetrating well under a constant-flux pumping in a confined aquifer of infinite horizontal extent. Later, many researchers had developed the solutions under some simplified conditions in a heterogeneous aquifer system. Examples of the solutions for pumping in confined aquifer systems are Barker and Herbert (1982), Butler (1988), Ruud and Kabala (1997), Cassiani and Kabala (1998), Yang et al. (2006), Zhan and Bian (2006), Chiu et al. (2007) among many others. Petroleum engineers also have great interest in the subject of dealing with oil migration across less permeable semi-confining layers (Streltsova 1988). The solutions in the petroleum industry include Bixel and van Poolen (1967), Jargon (1976), and Streltsova-Adams (1979) among many others. Cassiani and Kabala (1998) developed a semi-analytical solution for the mixed-type boundary value problem via dual integral equations for the constant-flux and slug tests at a partially penetrating well as well as accounting for wellbore storage, infinitesimal skin, and aquifer anisotropy. Zhan and Bian (2006) derived analytical solutions for describing the groundwater flow with steady-state leakages due to pumping subject to the conditions of maintaining constant flux and constant drawdown at the wells.

The literature regarding the slug test is briefly reviewed below. Ferris and Knowles (1954) originally pioneered the analysis procedure from the slug-test data. They provided an approximate solution for describing the water level change within the test well. Early related works were Bredehoeft et al. (1966), Cooper et al. (1967), and Bouwer and Rice (1976) with regard to the groundwater problems and Carslaw and Jaeger (1959, p. 342) in a heat conduction problem. Dougherty and Babu (1984) developed an analytical model to investigate the flow in a double-porosity reservoir. The transient solution for slug-test problems considering well partial penetration, wellbore effect, and skin effect was derived by utilizing numerical inversion of Laplace transform. Peres et al. (1989) presented a theoretical formula relating the solutions of slug test and constant-flux test at a fully penetrating well in confined aquifer systems considering the effect of wellbore storage. Yeh and Yang (2006) presented an analytical solution for slug tests to investigate the effects of skin type, skin thickness, and the contrast of skin transmissivity to formation transmissivity on dimensionless hydraulic head. Chen et al. (2007) derived a semianalytical solution based on a formula given by Peres et al. (1989) for the slug test performed in a confined aquifer with a partially penetrating well. They indicated that a smaller screen length, anisotropic ratio, or specific storage yields a slower recovery rate. Moreover, Yeh et al. (2008) also developed a semi-analytical solution for slug tests in a radial two-zone confined aquifer system considering the effects of the skin and well partial penetration.

Van Everdingen and Hurst (1949) developed a mathematical model for the flow problems and derived analytical solutions by using the Laplace transform method and superimposition theorem. They provided a relationship between the constant terminal pressure case with a transient wellbore flow rate and the constant terminal rate case with a transient pressure inside the well. Perina and Lee (2006) presented a general well function for pumping from a confined, leaky, or unconfined aquifer as well as considering the effects of finite-thickness skin and well partial penetration. Their semi-analytical solution was derived via Laplace and generalized finite Fourier transforms and allowed for non-uniform radial flux distribution along the well screen using a dsicrization approach which is essentially to divide the screen into several segments.

The purpose of this paper is to develop a general mathematical model for describing the hydraulic head as a result of the constant-head, constant-flux, and slug tests at a partially penetrating well in a radial confined aquifer. In the case of the constant-head test the water level is maintained at a constant at the wellbore and there is no pumping inside the well while in the case of constant-flux test the wellbore flow rate is assumed constant and the effect of wellbore storage is discounted. Moreover, in the case of the slug test the flow discharge/injection rate inside the well is considered equal to the flow across the screen. The solution of the model is developed by utilizing Laplace and finite Fourier cosine transforms. This new general solution can then be 
used to predict the hydraulic head distribution for one of the constant-head test, constant-flux test, and slug test performed at a partially penetrating well in a radial confined aquifer system. In addition, this general solution can further be simplified for the case that the aquifer system has a fully penetrating well.

\section{MATHEMATICAL DEVELOPMENT}

A general mathematical model is developed to describe the hydraulic head distribution in light of the constant-head, constant-flux, and slug tests in a confined radial aquifer as well as considering the effect of well partial penetration. Figure 1 shows the schematic representation for a partially penetrating well in a confined aquifer of infinite radial extent. The aquifer is overlain and underlain by impervious layers. The origin of the coordinate is located at the center of the test well which has a radius $r_{w}$. As demonstrated in the figure, the effective casing radius is denoted as $r_{c}$. The well partially penetrates the aquifer with a screen from $b_{1}$ to $b_{2}$ as shown in the figure. The wellbore storage of the aquifer is considered.

\subsection{Mathematical Model}

The equation representing the hydraulic head distribution, $h(r, z, t)$, in the aquifer system for the model described above can be written as [Batu 1998, p. 96, Eq. (2-174)]

$$
\begin{aligned}
& K_{r}\left[\frac{\partial^{2} h(r, z, t)}{\partial r^{2}}+\frac{1}{r} \frac{\partial h(r, z, t)}{\partial r}\right]+K_{z} \frac{\partial^{2} h(r, z, t)}{\partial z^{2}} \\
& =S_{s} \frac{\partial h(r, z, t)}{\partial t}
\end{aligned}
$$

where $K_{r}$ is the horizontal hydraulic conductivity; $K_{z}$ is the vertical hydraulic conductivity; $S_{s}$ is the specific storage; $r$ is the radial distance from the centerline of the test well; $z$ is the vertical distance from the impermeable layer; and $t$ is the time from the start of test.

The hydraulic head within the aquifer is initially assumed zero, this is

$$
h(r, z, 0)=0
$$

The hydraulic head at infinity is assumed zero; thus, the outer boundary condition is therefore given as

$$
h(\infty, z, t)=0
$$

According to Darcy's law, the boundary condition for the flow rate, $q_{s}(t)$, across the screen is expressed as
$K_{r} \frac{\partial h\left(r_{w}, z, t\right)}{\partial r}=q_{s}(t)\left[U\left(z-b_{1}\right)-U\left(z-b_{2}\right)\right], 0 \leq z \leq L$

where $L$ is the aquifer thickness and $U(\bullet)$ is a unit step function defining that $U\left(z-b_{i}\right)$ equals one when $b_{i} \leqq z$ and zero otherwise for $i=1$ or 2 .

The lower and upper boundary conditions are, respectively, given as

$\frac{\partial h(r, 0, t)}{\partial z}=0$

and

$$
\frac{\partial h(r, L, t)}{\partial z}=0
$$

\subsection{Continuity Equation for Wellbore Flow}

The pressure in the wellbore is assumed to be hydrostatic. The continuity equation for flow inside the wellbore is expressed as (see, van Everdingen and Hurst 1949)

$$
\left(\pi r_{c}^{2}\right) \frac{\partial h_{w}(t)}{\partial t}=-Q(t)+2 \pi r_{w}\left(b_{2}-b_{1}\right) q_{s}(t)
$$

where $h_{w}(t)$ is the well water level and $Q(t)$ is the pumping flow rate. The left-hand side term of Eq. (7) reflects the effect of wellbore storage and the second term on the right-hand side of Eq. (7) represents the total flow across the

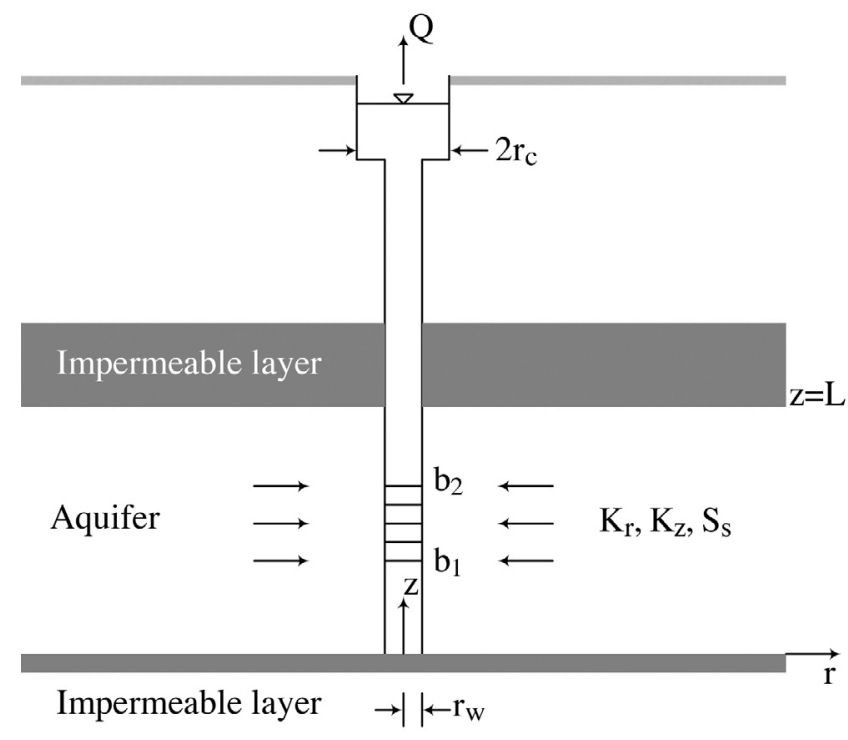

Fig. 1. The cross-section of a radial confined aquifer system with a partially penetrating well. 
screen. The well water level is equal to the average head in the aquifer just outside the wellbore, thus

$h_{w}(t)=h\left(r_{w}, z, t\right)$

The well water level equals the head rise (or drop) $h_{w 0}$ for the slug test when $t=0$, that is

$h_{w}(0)=h_{w 0}$

\subsection{Laplace-Domain Solution}

The methods of Laplace and finite Fourier cosine transforms are applied to solve Eq. (1) associated with the initial condition [Eq. (2)] and boundary conditions [Eqs. (3) - (6)] . The inverse finite Fourier transform is then applied to develop the solution of the hydraulic head within the aquifer. Applying the Laplace transform to Eq. (1) yields the following subsidiary equation

$\frac{\partial^{2} \bar{h}(r, z, p)}{\partial r^{2}}+\frac{1}{r} \frac{\partial \bar{h}(r, z, p)}{\partial r}+\xi \frac{\partial^{2} \bar{h}(r, z, p)}{\partial z^{2}}$

$=\zeta p \bar{h}(r, z, p)$

where $\bar{h}(r, z, p)$ is the hydraulic head in the Laplace domain; $p$ is the Laplace variable (Spiegel 1965); $\xi=K_{z} / K_{r}$; and $\zeta=S_{s} / K_{r}$. Equations (3) - (6) in the Laplace domain are, respectively,

$\bar{h}(\infty, z, p)=0$

$K_{r} \frac{\partial \bar{h}\left(r_{w}, z, p\right)}{\partial r}=\bar{q}_{s}(p)\left[U\left(z-b_{1}\right)-U\left(z-b_{2}\right)\right], 0 \leq z \leq L$

$\frac{\partial \bar{h}(r, 0, p)}{\partial z}=0$

and

$\frac{\partial \bar{h}(r, L, p)}{\partial z}=0$

With Eq. (8) and applying the Laplace transform to Eq. (7) results in

$\bar{q}_{s}(p)=\frac{1}{2 \pi r_{w}\left(b_{2}-b_{1}\right)}\left\{\left(\pi r_{c}^{2}\right)\left[p \bar{h}\left(r_{w}, z, p\right)-h_{w 0}\right]+\bar{Q}(p)\right\}$
Applying the finite Fourier cosine transform to Eqs. (10) - (12) after substituting Eq. (15) into Eq. (12) obtains

$\tilde{h}\left(r, w_{n}, p\right)=$

$\frac{\left[\left(\pi r_{c}^{2}\right) h_{w 0}-\bar{Q}(p)\right] W\left(b_{1}, b_{2}\right)}{\left(\pi r_{c}^{2}\right) p K_{0}\left(\alpha_{1} r_{w}\right)+2 \pi r_{w} K_{r}\left(b_{2}-b_{1}\right) \alpha_{1} K_{1}\left(\alpha_{1} r_{w}\right)} K_{0}\left(\alpha_{1} r\right)$

where $\tilde{h}\left(r, w_{n}, p\right)$ is the transformed hydraulic head; $W\left(b_{1}\right.$, $\left.b_{2}\right)=\left[\sin \left(w_{n} b_{2}\right)-\sin \left(w_{n} b_{1}\right)\right] / w_{n} ; w_{n}=n \pi / L, n=0,1,2, \ldots ;$ $\alpha_{1}^{2}=\xi w_{n}^{2}+\zeta p$; and $K_{0}(\bullet)$ and $K_{1}(\bullet)$ are the modified Bessel functions of the second kind of order zero and one, respectively.

Applying the inverse finite Fourier transform to Eq. (16) yields

$\bar{h}(r, z, p)=$

$\frac{1}{L} \frac{\left[\left(\pi r_{c}^{2}\right) h_{w 0}-\bar{Q}(p)\right]\left(b_{2}-b_{1}\right)}{\left(\pi r_{c}^{2}\right) p K_{0}\left(\alpha_{2} r_{w}\right)+2 \pi r_{w} K_{r}\left(b_{2}-b_{1}\right) \alpha_{2} K_{1}\left(\alpha_{2} r_{w}\right)} K_{0}\left(\alpha_{2} r\right)+$

$\frac{2}{L} \sum_{n=1}^{\infty} \frac{\left[\left(\pi r_{c}^{2}\right) h_{w 0}-\bar{Q}(p)\right] W\left(b_{1}, b_{2}\right)}{\left(\pi r_{c}^{2}\right) p K_{0}\left(\alpha_{1} r_{w}\right)+2 \pi r_{w} K_{r}\left(b_{2}-b_{1}\right) \alpha_{1} K_{1}\left(\alpha_{1} r_{w}\right)} K_{0}\left(\alpha_{1} r\right)$

$\cos \left(w_{n} z\right)$

where $\alpha_{2}^{2}=\zeta p$. Equation (17) is the Laplace-domain solution for hydraulic head in the confined aquifer system considering a pumping flow rate and wellbore storage of the partially penetrating well. Since this solution comprises the products of the Bessel and cosine functions and is rather complicated, its inverse Laplace transforms, i.e., time domain solution, may not be tractable. The numerical Laplace inversion such as the Stehfest method (Stehfest 1970; Chang and Yeh 2009) or Crump method (Crump 1976; Chen et al. 2007) can be adopted to evaluate the corresponding timedomain result.

\section{SPECIAL CASES FOR THREE TYPES OF AQUI- FER TESTS}

In engineering practices, the constant-head, constantflux, and slug tests are commonly employed for the investigation of aquifer characteristics. The solution for the aquifer tests can be used to generate the type curves if a graphical method is considered to analyze the observed test data. The Laplace-domain solution for the hydraulic head due to one of the aquifer tests is presented separately in the following three sections.

\subsection{Constant-Head Test}

For the constant-head test, the well water level denoted 
as $h_{0}$ is maintained at a constant; there is no need to consider the wellbore storage. The Laplace-domain solution of the test performed at a partially penetrating well can be obtained from Eq. (17) as

$$
\begin{aligned}
\bar{h}(r, z, p)= & -\bar{Q}(p)\left[\frac{1}{L} \frac{K_{0}\left(\alpha_{2} r\right)}{2 \pi r_{w} K_{r} \alpha_{2} K_{1}\left(\alpha_{2} r_{w}\right)}+\right. \\
& \left.\frac{2}{L} \sum_{n=1}^{\infty} \frac{W\left(b_{1}, b_{2}\right) K_{0}\left(\alpha_{1} r\right)}{2 \pi r_{w} K_{r}\left(b_{2}-b_{1}\right) \alpha_{1} K_{1}\left(\alpha_{1} r_{w}\right)} \cos \left(w_{n} z\right)\right]
\end{aligned}
$$

where $\bar{Q}(p)$, the pumping flow rate in the Laplace domain is unknown and can be obtained by substituting the result of Laplace transform of Eq. (9) into Eq. (18) as

$$
\begin{aligned}
\bar{Q}(p)= & -\frac{h_{0}}{p}\left[\frac{1}{L} \frac{K_{0}\left(\alpha_{2} r_{w}\right)}{2 \pi r_{w} K_{r} \alpha_{2} K_{1}\left(\alpha_{2} r_{w}\right)}+\right. \\
& \left.\frac{2}{L} \sum_{n=1}^{\infty} \frac{W^{2}\left(b_{1}, b_{2}\right) K_{0}\left(\alpha_{1} r_{w}\right)}{2 \pi r_{w} K_{r}\left(b_{2}-b_{1}\right) \alpha_{1} K_{1}\left(\alpha_{1} r_{w}\right)}\right]^{-1}
\end{aligned}
$$

For the case of the fully penetrating well, the screen interval parameters are $b_{1}=0$ and $b_{2}=L$. Thus, the variable $W\left(b_{1}, b_{2}\right)$ is equal to zero. The Laplace-domain solution for the hydraulic head then reduces to

$\bar{h}(r, p)=-\frac{h_{0}}{p} \frac{K_{0}\left(\alpha_{2} r\right)}{K_{0}\left(\alpha_{2} r_{w}\right)}$

Note that Eq. (19) is equivalent to the dimensionless solution given by Yang and Yeh [2005, p. 213, Eq. (56)] for the case of well partial penetration and Eq. (20) is equivalent to the one by Yang and Yeh [2005, p. 213, Eq. (61)] for the case of full penetration.

\subsection{Constant-Flux Test}

For the constant-flux test, the pumping rate is maintained at a constant and the effect of wellbore storage on the hydraulic head, which occurs at early time of pumping, is generally negligible. The Laplace-domain solution of the constant-flux test at a partially penetrating well can be obtained from Eq. (17) as

$$
\begin{aligned}
\bar{h}(r, z, p)= & \frac{-Q}{4 \pi T} \frac{2}{r_{w}} \frac{K_{0}\left(\alpha_{2} r\right)}{p \alpha_{2} K_{1}\left(\alpha_{2} r_{w}\right)}+ \\
& \frac{-Q}{4 \pi T} \frac{4}{\left(b_{2}-b_{1}\right) r_{w}} \sum_{n=1}^{\infty} \frac{W\left(b_{1}, b_{2}\right) K_{0}\left(\alpha_{1} r\right)}{p \alpha_{1} K_{1}\left(\alpha_{1} r_{w}\right)} \cos \left(w_{n} z\right)
\end{aligned}
$$

where $T=K_{r} L$ is the aquifer transmissivity. Note that this solution is also given in Yang et al. [2006, p. 2, Eq. (7)].

For the case of a full penetration, the solution of aquifer hydraulic head in Laplace domain then reduces to

$\bar{h}(r, p)=\frac{-Q}{4 \pi T} \frac{2}{r_{w}} \frac{K_{0}\left(\alpha_{2} r\right)}{p \alpha_{2} K_{1}\left(\alpha_{2} r_{w}\right)}$

which is also presented in Yang and Yeh [2009, p. 3385, Eq. (34)].

\subsection{Slug Test}

For the slug test, there is no pumping, therefore $Q(t)$ $=0$. The Laplace-domain solution for the head distribution can then be obtained from Eq. (17) as

$$
\begin{aligned}
& \bar{h}(r, z, p)= \\
& \frac{1}{L} \frac{\left[\left(\pi r_{c}^{2}\right) h_{w 0}\right]\left(b_{2}-b_{1}\right)}{\left(\pi r_{c}^{2}\right) p K_{0}\left(\alpha_{2} r_{w}\right)+2 \pi r_{w} K_{r}\left(b_{2}-b_{1}\right) \alpha_{2} K_{1}\left(\alpha_{2} r_{w}\right)} K_{0}\left(\alpha_{2} r\right)+ \\
& \frac{2}{L} \sum_{n=1}^{\infty} \frac{\left[\left(\pi r_{c}^{2}\right) h_{w 0}\right] W\left(b_{1}, b_{2}\right)}{\left(\pi r_{c}^{2}\right) p K_{0}\left(\alpha_{1} r_{w}\right)+2 \pi r_{w} K_{r}\left(b_{2}-b_{1}\right) \alpha_{1} K_{1}\left(\alpha_{1} r_{w}\right)} K_{0}\left(\alpha_{1} r\right) \\
& \cdot \cos \left(w_{n} z\right)
\end{aligned}
$$

This equation is the same as the one presented in Chen et al. [2007, p. 63, Eq. (12)] for the slug test performed in a partially penetrating well. For aquifers with a fully penetrating well, Eq. (23) can be reduced to

$$
\begin{aligned}
\bar{h}(r, p) & =\frac{\left[\left(\pi r_{c}^{2}\right) h_{w 0}\right] K_{0}\left(\alpha_{2} r\right)}{\left(\pi r_{c}^{2}\right) p K_{0}\left(\alpha_{2} r_{w}\right)+2 \pi r_{w} K_{r} L \alpha_{2} K_{1}\left(\alpha_{2} r_{w}\right)} \\
& =\frac{h_{w 0} r_{w} S K_{0}\left(\alpha_{2} r\right)}{T \alpha_{2}\left[r_{w} \alpha_{2} K_{0}\left(\alpha_{2} r_{w}\right)+2\left(S \frac{r_{w}^{2}}{r_{c}^{2}}\right) K_{1}\left(\alpha_{2} r_{w}\right)\right]}
\end{aligned}
$$

where $S$ is the aquifer storage coefficient. Equation (24) was also given in Cooper et al. (1967) and Yeh and Yang (2006, p. 1484, Eq. (43)].

\subsection{Summary}

To summarize, this new solution has been shown to reduce to the solution for one of the aquifer tests performed at a fully or partially penetrating well as shown in Table 1 . The main advantage of having this solution is that a single computer program can be developed based on this solution when coupled with the extended Kalman filter (e.g., Leng and Yeh 2003; Yeh and Huang 2005) or a heuristic optimization approach such as genetic algorithm (e.g., Lin and Yeh 2005) or simulated annealing (e.g., Yeh and Chen 
Table 1. A summary of the solutions for various types of aquifer tests at a fully or partially penetrating well in a radial confined aquifer.

\begin{tabular}{|c|c|c|c|c|c|}
\hline \multirow{2}{*}{ Type } & \multirow{2}{*}{ Well penetration } & \multicolumn{3}{|c|}{ Conditions } & \multirow{2}{*}{ Solutions } \\
\hline & & Wellbore storage & Flow rate & Hydraulic head & \\
\hline \multirow{2}{*}{ Constant-head test } & partial & \multirow{2}{*}{ No } & \multirow{2}{*}{$Q(t)$} & $h_{0}^{* *}$ & Yang and Yeh (2005) \\
\hline & full & & & $h_{0}^{* *}$ & Yang and Yeh (2005) \\
\hline \multirow{2}{*}{ Constant-flux test } & partial & \multirow{2}{*}{ No } & \multirow{2}{*}{$Q^{*}$} & $h(r, z, t)$ & Yang et al. (2006) \\
\hline & full & & & $h(r, t)$ & Yang and Yeh (2009) \\
\hline \multirow{2}{*}{ Slug test } & partial & \multirow{2}{*}{ Yes } & \multirow{2}{*}{ No } & $h(r, z, t)$ & Chen et al. (2007) \\
\hline & full & & & $h(r, t)$ & Yeh and Yang (2006); Cooper et al. (1967) \\
\hline
\end{tabular}

Note: $* Q$ represents a constant flow rate; $* * h_{0}$ represents a constant hydraulic head.

2007; Yeh et al. 2007) to analyze observed aquifer test data for the estimation of the aquifer parameters.

\section{CONCLUDING REMARKS}

A general mathematical model describing the transient hydraulic head in a radial confined aquifer system with a partially penetrating well has been developed for three widely used aquifer tests, i.e., the constant-head test, constant-flux test, and slug test. The solution in the Laplace domain is derived by applying the methods of the Laplace and finite Fourier cosine transforms. In addition, the solution for each of those three aquifer tests in aquifers with a fully penetrating well is also provided. This solution has been shown to reduce to the solution of constant-head test when the well water level is maintained constant and become the solution of constant-flux test if the pumping rate is kept constant. In addition, this solution also reduces to the solution of slug test when the pumping rate is set zero. Obviously, this newly derived solution can be considered a general solution for dealing six different aquifer test problems for the test well either fully or partially penetrated.

Acknowledgements Research leading to this paper has been partially supported by the grants from Taiwan National Science Council under the contract numbers NSC 99-2221-E-009-062-MY3, NSC 100-2221-E-009-106, and NSC 101-3113-E-007-008. The authors would like to thank the guest editor and anonymous reviewers for their valuable and constructive comments that help improve the clarity of our presentation.

\section{REFERENCES}

Barker, J. A. and R. Herbert, 1982: Pumping tests in patchy aquifers. Ground Water, 20, 150-155, doi: 10.1111/j. 1745-6584.1982.tb02742.x. [Link]

Batu, V., 1998: Aquifer Hydraulics: A Comprehensive
Guide to Hydrogeological Data Analysis. John Wiley and Sons, New York.

Bixel, H. C. and H. K. van Poollen, 1967: Pressure drawdown and buildup in the presence of radial discontinuities. Soc. Petrol. Eng., 7, 301-309, doi: 10.2118/1516PA. [Link]

Bouwer, H. and R. C. Rice, 1976: A slug test for determining hydraulic conductivity of unconfined aquifers with completely or partially penetrating wells. Water Resour.Res., 12, 423-428, doi: 10.1029/WR012i003p004 23. [Link]

Bredehoeft, J. D., H. H. Jr. Cooper, and I. S. Papadopulos, 1966: Inertial and storage effects in well-aquifer systems: An analog investigation. Water Resour. Res., 2, 697-707, doi: 10.1029/WR002i004p00697. [Link]

Butler, Jr. J. J., 1988: Pumping tests in nonuniform aquifers - The radially symmetric case. J. Hydrol., 101, 15-30, doi: 10.1016/0022-1694(88)90025-X. [Link]

Carslaw, H. S. and J. C. Jaeger, 1959: Conduction of Heat in Solids. $2^{\text {nd }}$ Ed., Oxford, Clarendon.

Cassiani, G. and Z. J. Kabala, 1998: Hydraulics of a partially penetrating well: Solution to a mixed-type boundary value problem via dual integral equations. J. Hydrol., 211, 100-111, doi: 10.1016/S0022-1694(98)00223-6. [Link]

Cassiani, G., Z. J. Kabala, and M. A. Jr. Medina, 1999: Flowing partially penetrating well: Solution to a mixed-type boundary value problem. Adv. Water Resour., 23, 5968, doi: 10.1016/S0309-1708(99)00002-0. [Link]

Chang, C. C. and C. S. Chen, 2002: An integral transform approach for a mixed boundary problem involving a flowing partially penetrating well with infinitesimal well skin. Water Resour. Res., 38, 1071, doi: 10.1029/ 2001WR001091. [Link]

Chang, Y. C. and H. D. Yeh, 2009: New solutions to the constant-head test performed at a partially penetrating well. J. Hydrol., 369, 90-97, doi: 10.1016/j.jhydrol.2009.02.016. [Link] 
Chen, Y. J., H. D. Yeh, and S. Y. Yang, 2007: A new semianalytical solution for slug test in a confined aquifer under the effects of well partial penetration. Hydrosci. Hydraul. Eng., JSCE, 25, 59-74.

Chiu, P. Y., H. D. Yeh, and S. Y. Yang, 2007: A new solution for a partially penetrating constant-rate pumping well with a finite-thickness skin. Int. J. Numer. Anal. Methods Geomech., 31, 1659-1674, doi: 10.1002/nag. 607. [Link]

Cooper, Jr. H. H., J. D. Bredehoeft, and I. S. Papadopulos, 1967: Response of a finite-diameter well to an instantaneous charge of water. Water Resour. Res., 3, 263-269, doi: 10.1029/WR003i001p00263. [Link]

Crump, K. S., 1976: Numerical inversion of Laplace transforms using a Fourier series approximation. J. Assoc. Comput. Mach., 23, 89-96, doi: 10.1145/321921.3219 31. [Link]

Dougherty, D. E. and D. K. Babu, 1984: Flow to a partially penetrating well in a double-porosity reservoir. Water Resour. Res., 20, 1116-1122, doi: 10.1029/WR 020i008p01116. [Link]

Ferris, J. G. and D. B. Knowles, 1954: The Slug Test for Estimating Transmissibility. US Department of the Interior, Geological Survey, Water Resources Division, Ground Water Branch, 7 pp.

Hantush, M. S., 1957: Nonsteady flow to a well partially penetrating an infinite leaky aquifer. Proc. Iraq. Sci. Soc., 1, 10-19.

Hantush, M. S., 1961a: Drawdown around a partially penetrating well. Proc. Am. Soc. Civil Engrs., 87, HY4, 83-98.

Hantush, M. S., 1961b: Aquifer tests on partially penetrating wells. Proc. Am. Soc. Civil Engrs., 87, HY5, 171-195.

Hantush, M. S., 1964: Hydraulics of wells. In: Chow, V. T. (Ed.), Advances in Hydroscience, Vol. 1, Academic Press, New York.

Jargon, J. R., 1976: Effect of wellbore storage and wellbore damage at the active well on interference test analysis. J. Petrol. Technol., 28, 851-858, doi: 10.2118/5795PA. [Link]

Kirkham, D., 1959: Exact theory of flow into a partially penetrating well. J. Geophy. Res., 64, 1317-1327, doi: 10.1029/JZ064i009p01317. [Link]

Leng, C. H. and H. D. Yeh, 2003: Aquifer parameter identification using the extended Kalman filter. Water Resour. Res., 39, 1062, doi: 10.1029/2001WR000840. [Link]

Lin, Y.C. and H.D. Yeh, 2005: Trihalomethane species forecast using optimization methods: genetic algorithms and simulated annealing. J. Comput. Civil Eng., 19, 248-257, doi: 10.1061/(ASCE)0887-3801(2005)19:3 (248). [Link]

Novakowski, K. S., 1993: Interpretation of the transient flow rate obtained from constant-head tests conducted in situ in clays. Can. Geotech. J., 30, 600-606, doi: 10.1139/t93-052. [Link]

Peres, A. M. M., M. Onur, and A.C. Reynolds, 1989: A new analysis procedure for determining aquifer properties from slug test data. Water Resour. Res., 25, 1591-1602, doi: 10.1029/WR025i007p01591. [Link]

Perina, T. and T. C. Lee, 2006: General well function for pumping from a confined, leaky, or unconfined aquifer. J. Hydrol., 317, 239-260, doi: 10.1016/j.jhydrol.2005. 05.020. [Link]

Ruud, N. C. and Z. J. Kabala, 1997: Response of a partially penetrating well in a heterogeneous aquifer: Integrated well-face flux vs. uniform well-face flux boundary conditions. J. Hydrol., 194, 76-94, doi: 10.1016/ S0022-1694(96)03217-9. [Link]

Spiegel, M. R., 1965: Laplace Transforms, Schaum's Outlines, McGraw-Hill, New York.

Stehfest, H., 1970: Algorithm 368, Numerical inversion of Laplace transforms. Commun. ACM, 13, 47-49, doi: 10.1145/361953.361969. [Link]

Streltsova, T. D., 1988: Well Testing in Heterogeneous Formations. John Wiley \& Sons Canada, Ltd., New York, USA, $448 \mathrm{pp}$.

Streltsova-Adams, T. D., 1979: Pressure drawdown in a well with limited flow entry. J. Petrol. Technol., 31, 1469-1476, doi: 10.2118/7486-PA. [Link]

van Everdingen, A. F. and W. Hurst, 1949: The application of the Laplace transformation to flow problems in Reservoirs. J. Petrol. Technol., 1, 305-324, doi: 10.21 18/949305-G. [Link]

Yang, S. Y. and H. D. Yeh, 2005: Laplace-domain solutions for radial two-zone flow equations under the conditions of constant-head and partially penetrating well. J. Hydraul. Eng., 131, 209-216, doi: 10.1061/(ASCE)07339429(2005)131:3(209). [Link]

Yang, S. Y. and H. D. Yeh, 2009: Radial groundwater flow to a finite diameter well in a leaky confined aquifer with a finite-thickness skin. Hydrol. Process., 23, 3382-3390, doi: 10.1002/hyp.7449. [Link]

Yang, S. Y., H. D. Yeh, and P. Y. Chiu, 2006: A closed form solution for constant flux pumping in a well under partial penetration condition. Water Resour. Res., 42 W05502, 1-8, doi: 10.1029/2004WR003889. [Link]

Yeh, H. D., 1987: Theis' solution by nonlinear least-squares and finite-difference Newton's method. Ground Water, 25, 710-715, doi: 10.1111/j.1745-6584.1987.tb022 12.x. [Link]

Yeh, H. D and Y. C. Huang, 2005: Parameter estimation for leaky aquifers using the extended Kalman filter, and considering model and data measurement uncertainties. J. Hydrol., 302, 28-45, doi: 10.1016/j.jhydrol. 2004.06.035. [Link]

Yeh, H. D. and S. Y. Yang, 2006: A novel analytical solution for a slug test conducted in a well with a finite- 
thickness skin. Adv. Water Resour., 29, 1479-1489, doi: 10.1016/j.advwatres.2005.11.002. [Link]

Yeh, H. D. and Y. J. Chen, 2007: Determination of skin and aquifer parameters for a slug test with wellboreskin effect. J. Hydrol., 342, 283-294, doi: 10.1016/j. jhydrol.2007.05.029. [Link]

Yeh, H. D., Y. C. Lin, and Y. C. Huang, 2007: Parameter identification for leaky aquifers using global optimization methods. Hydrol. Process., 21, 862-872, doi: 10.1002/hyp.6274. [Link]

Yeh, H. D., Y. J. Chen, and S. Y. Yang, 2008: Semi-analytical solution for a slug test in partially penetrating wells including the effect of finite-thickness skin. $\mathrm{Hy}$ drol. Process., 22, 3741-3748, doi: 10.1002/hyp.6978. [Link]

Zhan, H. and A. Bian, 2006: A method of calculating pumping induced leakage. J. Hydrol., 328, 659-667, doi: 10.1016/j.jhydrol.2006.01.010. [Link] 